\title{
Soil-gas helium and surface-waves detection of fault zones in granitic bedrock
}

\author{
G K Reddy, T Seshunarayana, Rajeev Menon and P Senthil Kumar* \\ National Geophysical Research Institute, Hyderabad 500 606, India. \\ *e-mail: senthilngri@yahoo.com
}

\begin{abstract}
Fracture and fault networks are conduits that facilitate groundwater movement in hard-rock terrains. Soil-gas helium emanometry has been utilized in Wailapally watershed, near Hyderabad in southern India, for the detection of fracture and fault zones in a granite basement terrain having a thin regolith. Based on satellite imagery and geologic mapping, three sites were selected for detailed investigation. High spatial resolution soil-gas samples were collected at every one meter at a depth of $>1.5 \mathrm{~m}$ along $100 \mathrm{~m}$ long profiles (3 in number). In addition, deep shear-wave images were also obtained using the multichannel analysis of surface waves. The study clearly indicates several soil-gas helium anomalies (above $200 \mathrm{ppb}$ ) along the profiles, where the shear-wave velocity images also show many near-surface vertical low velocity zones. We thus interpret that the soil-gas helium anomalous zones and the vertical low-velocity zones are probable traces of fault/fracture zones that could be efficient natural recharge zones and potential groundwater conduits. The result obtained from this study demonstrates the efficacy of an integrated approach of soil-gas helium and the seismic methods for mapping groundwater resource zones in granite/gneiss provinces.
\end{abstract}

\section{Introduction}

Near-surface groundwater is a vital resource for agriculture, industry and human consumption. Therefore groundwater exploration gains emphasis for meeting the steadily increasing demand for water especially when draught conditions prevail. Fracture and fault networks form an important groundwater resource zone in hard rock terrains. A significant portion of the investigated area exposes hard-rocks such as granites and gneisses that may extend to several kilometers from the surface to deep crustal interiors. For example, the Archaean cratons constitute about $70 \%$ gneisses and granites (Condie 1993). These crystalline hardrocks are poor groundwater reservoir rocks, in which the inherent porosity is absent. However, these rocks are rendered porous and permeable when they are intersected by fractures and faults that form in response to tectonic processes. These structures are then capable of not only holding large volume of groundwater but also transporting surface water to the deeper levels of the earth's crust. Hence, precise mapping of these structures and imaging their deep interiors through geological, geochemical and geophysical methods is very important for fruitful exploration of groundwater resource zones. The imaging of deep interiors is also important in geotechnical applications and is useful in earthquake hazard assessment. Although conventional geological mapping would provide the surface distribution of these structures, it is met with severe uncertainty, where the rocks are enveloped with thick alluvium. In such a situation, geophysical and geochemical techniques may aid in deciphering their surface and depth distribution.

The soil-gas helium emanometry is an excellent geochemical tool capable of detecting fault and fracture zones. For example, soil-gas helium anomalies are found along the earthquake surface rupture zones as well as seismically reactivated

Keywords. Soil-gas helium; surface-waves; faults and fractures; groundwater; granite basement. 


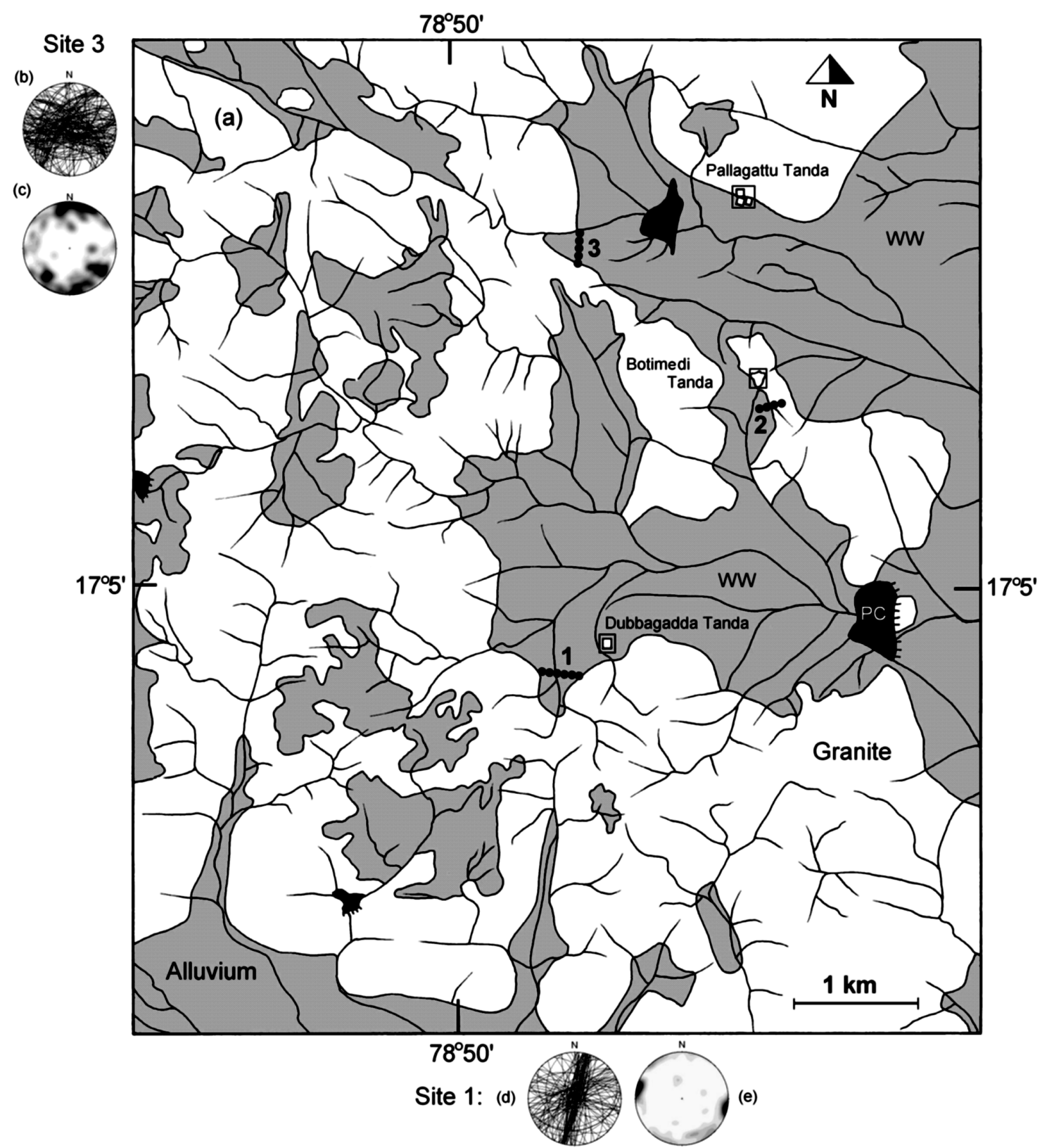

Figure 1. (a) Geological map of southeastern Hyderabad showing the three sites (Seshunarayana et al 2008a), where the soil-gas helium and MASW surveys were conducted. Equal-area plots of great circles (b and $\mathbf{d}$ ) and pole density contours (c and $\mathbf{e}$ ) show the orientations of faults and fractures in the granite exposures close to the survey areas. Abbreviations: WW - Wailapally watershed; PC - Pedda Cheruvu (a small dry reservoir exposing lake sediments).

pre-existing fault zones (e.g., Reimer 1985; Rao et al 1994; Toutain and Baubron 1999; Gupta et al 1999). Although the method has been extensively used in locating seismogenic faults (see Toutain and Baubron 1999), it also promises great potential to be used as a groundwater resource-mapping tool. In addition, there also exists the availability of many shallow geophysical imaging techniques for groundwater studies (e.g., electrical, magnetic, electromagnetic and microgravity). However, the multichannel analysis of surface waves (MASW) technique is an excellent newly emerging seismic method that has been extensively used in near surface geophysical investigations (e.g., Xia et al 2002; Xu and Butt 2006; Seshunarayana et al 2006; 2008a; 2008b). The MASW technique uses surface waves generated from an artificial point energy source (e.g., sledgehammer shots). Using frequency-phase velocity relation of fundamental mode surface waves, shear wave velocity-depth distribution up to a depth of 30 to $50 \mathrm{~m}$ can be modeled. The velocity-depth sections would be able to depict densely fractured areas (with or without chemical weathering) 

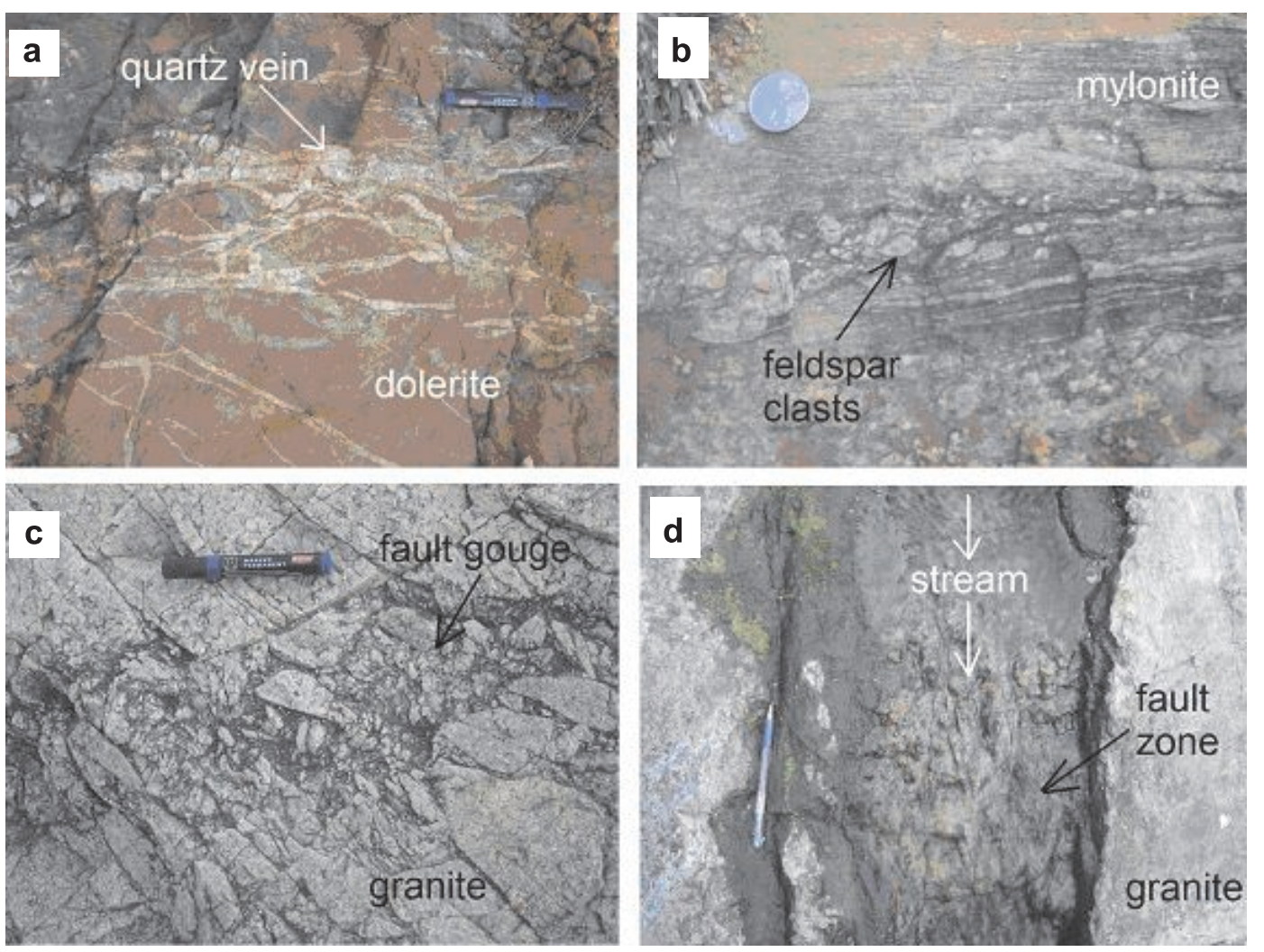

Figure 2. Photographs illustrating the faults and fractures in the study area. (a) A thin dolerite dyke intrudes a fault zone near profile 1; the dyke is brecciated and invaded by thin quartz veins that have also undergone shearing, indicating more than one episode of faulting. (b) A thin granite mylonite band is exposed near profile 2; note the feldspar porphyroclasts show rotation. (c) Fault gouge in the coarse-grained granite near profile 3; the gouge materials are composed of granite angular clasts surrounded by fine-grained matrix; water circulation along the fault lead to chemical alteration producing clayey materials. (d) A stream flow along the fault zone near profile 3. Note the increase of stream incision in the fault zone.

that are characterized by lower velocities than the adjoining rocks.

In this contribution, we show the results of the integrated MASW and soil-gas helium surveys in the Wailapally watershed, which is a type example for a small-scale watershed development in a granite province of Hyderabad (figure 1). Catchment areas of this watershed expose fractured and faulted (or sheared) granite basement. The geological setting provides an excellent opportunity to test the efficacy of soil-gas helium emanometry and MASW as groundwater resource mapping tools. This study has been undertaken in a zone where the geophysical and geochemical results can be verified by the surface geology.

\section{Geology}

The study area (Wailapally watershed) is located $\sim 75 \mathrm{~km}$ ESE of Hyderabad city. It belongs to the Hyderabad granite terrain, which is a part of $\sim 2.7-2.5 \mathrm{Ga}$ old eastern Dharwar craton (e.g., Chadwick et al 2000; Kumar and Reddy 2004). The Wailapally basin consists of a catchment area in the west and alluvial plains to the east. The Mula Nala and its tributaries form the drainage network of this watershed (figure 1). The catchment area is composed of granite massifs, which show topographic undulations. The drainage network in the catchment forms a rectangular pattern that would point to fracture controls (figure 1). The IRS-1D satellite image clearly shows two dominant sets of lineaments in this region. They are N-S to NE-SW, and ESE-WNW oriented lineaments. They express themselves as narrow, linear valleys forming one of the main drainage systems of the Wailapally basin. These lineaments cut across the granite massifs and probably extend to adjoining plain regions, where they may exist beneath the alluvial cover. Preferential weathering along these structures has produced valleys and gullies, which represent the present day drainage network. Previous ground structural analysis has identified the lineaments as faults, fractures and dykes. The orientations of the lineaments observed in the IRS-1D images are broadly similar to the orientations of the faults and fractures studied in the field (figures 1 and 2). We have selected three geophysical profiles that are near the mouth of the 
valleys formed from the fault and fracture zones (figure 1). The site descriptions are as follows:

\subsection{Profile 1 near Dubbagadda Tanda}

An approximately 120-m long east-west survey profile was selected across the N-S oriented valley. The dominant rock type is pink-colour porphyritic granite that contains quartz, K-feldspar and biotite. A dry stream occurs along the valley floor that coincides with a $15-20 \mathrm{~m}$ wide, N-S to NNE-SSW, sub-vertical brittle to brittle-ductile fault zone in the upstream direction. There exists a subordinate amount of NE-SW and ESE-WNW fractures. The N-S fault zones commonly exhibit a right-lateral strike-slip movement. Thin quartz and dolerite veins are emplaced through the fault zone, but are deformed intensely, suggesting their syn-tectonic emplacement (figure 2a). Some of the faults are associated with pseudotachylyte veins, which are proven indicators of seismic faulting.

\subsection{Profile 2 near Botimedi Tanda}

This is an ideal site for characterizing a fault zone covered with a relatively thick weathering cap and a little soil cover. The bedrock is massive, pink coloured, porphyritic granite. The weathering cap retains relict mineralogy and texture of the underlying granite. The thickness of the weathering cap varies from a few centimeters to meters, and has closely spaced sheet joints near the surface. A 2-4m wide, NW-SE striking, sub-vertical, fault zone is also exposed near the survey profile (figure 2b). A 90-m long seismic traverse was chosen in a roughly ENE-WSW direction. The soil-gas helium survey profile was limited to $40 \mathrm{~m}$ covering the fault exposures, because the rest of the profile is unsuitable for soil-gas sampling owing to the hard weathering cap.

\subsection{Profile 3 near Pallagattu Tanda}

A 130-m long, N-S oriented survey profile was selected at the mouth of the ESE-WNW valley. The rocks exposed in this valley are porphyritic granite and coarse-grained granite. These rocks are pinkcoloured, massive, homogeneous, and have primary foliations at places. Pegmatites and aplites are the late phases invading the granites. Mafic microgranular enclaves and xenolithic amphibolites are common. Rock exposures in the valley show evidence of fracturing and faulting (figure 2c). The main fracture/fault system strikes in ESE-WNW direction and dips sub-vertically. There are other sets of sub-vertical fractures in the N-S to NNESSW directions. At places, these fractures are filled with pseudotachylyte veins. There are structurally controlled springs in this valley and that supplies water to streams (figure 2d), but water disappears in the down stream direction because of enhanced recharge along the streambed.

\section{Data}

High spatial resolution soil-gas helium surveys were carried out over the fault/fracture zones, along the three profiles (figure 1). The soilgas samples were collected from a depth of $\sim 1.5 \mathrm{~m}$. A sampling interval of 1 meter was maintained along the profiles in an effort to precisely map the fracture/fault zones. The instrument used for the soil-gas helium analysis is an Alcatel Model ASM $100 \mathrm{~T}$ helium leak detector, whose sample inlet system was suitably modified to measure the soil-gas helium abundance. The helium concentration was measured to a precision of $20 \mathrm{ppb}$ at $5000 \mathrm{ppb}$ concentration level and the helium values are shown as excesses over the atmospheric abundance of $5240 \mathrm{ppb}$. The regional background value for soil-gas helium in the Wailapally area is $\sim 80-110$ ppb above the atmospheric helium abundance. The values registered above the background level are considered as anomalous.

The shear-wave velocity sections for the three profiles were obtained by modeling the MASW data (Seshunarayana et al 2008a), following the standard procedures (Miller et al 1999; Park et al 1999; Xu et al 2006). Rayleigh wave data (rich in ground-role) were recorded using an engineering seismograph (Strata View, manufactured by Geometrics Inc, USA) and 24 low-frequency $4.5 \mathrm{~Hz}$ vertical geophones, placed at $1 \mathrm{~m}$ interval. Acoustic energy was generated using a $10-\mathrm{kg}$ sledgehammer hit on a metal plate. The near offset was chosen between 5 and $10 \mathrm{~m}$, depending upon the site conditions. The shot interval is $1 \mathrm{~m}$. The acquired surface wave data were processed using the SurfSeis software of Kansas Geological Survey. Each set of Rayleigh wave data (shot gather) were transformed from time domain to frequency domain to generate dispersion curves (frequency vs. phase velocity), which have been further transformed into shear-wave velocity-depth profile through an inversion process. Each set of velocity-depth profiles was arranged in a sequential order from the first shot station to form a 2-D shear wave velocity field. For more details of the methodology, see Seshunarayana et al (2008a).

\section{Discussion}

The soil-gas helium and MASW methods independently detect the fault/fracture zones in the 


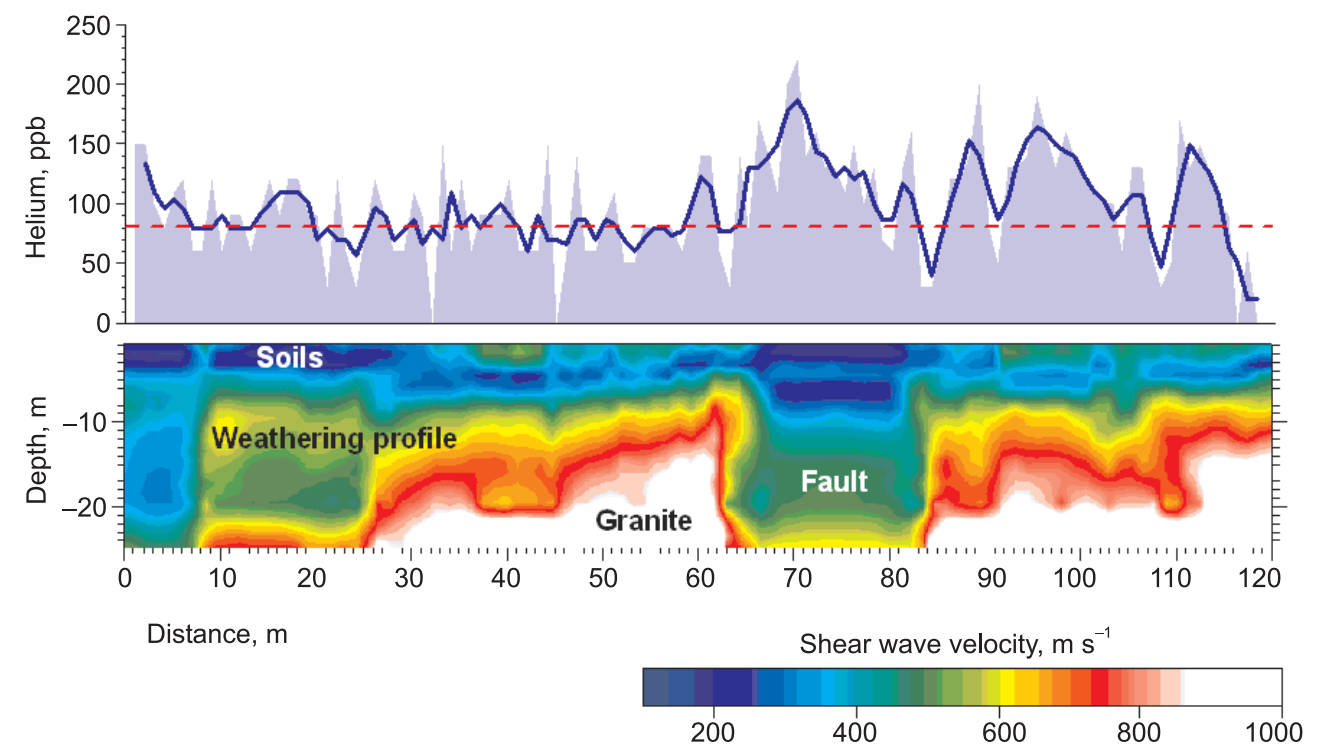

Figure 3. The shear wave velocity section and the soil-gas helium abundance along the profile 1. The original helium profile is superimposed by a three-point moving average plot (a thick blue line). The background soil-gas helium abundance along the profile is $80 \mathrm{ppb}$ above the atmospheric abundance of $5240 \mathrm{ppb}$ (a dashed line).
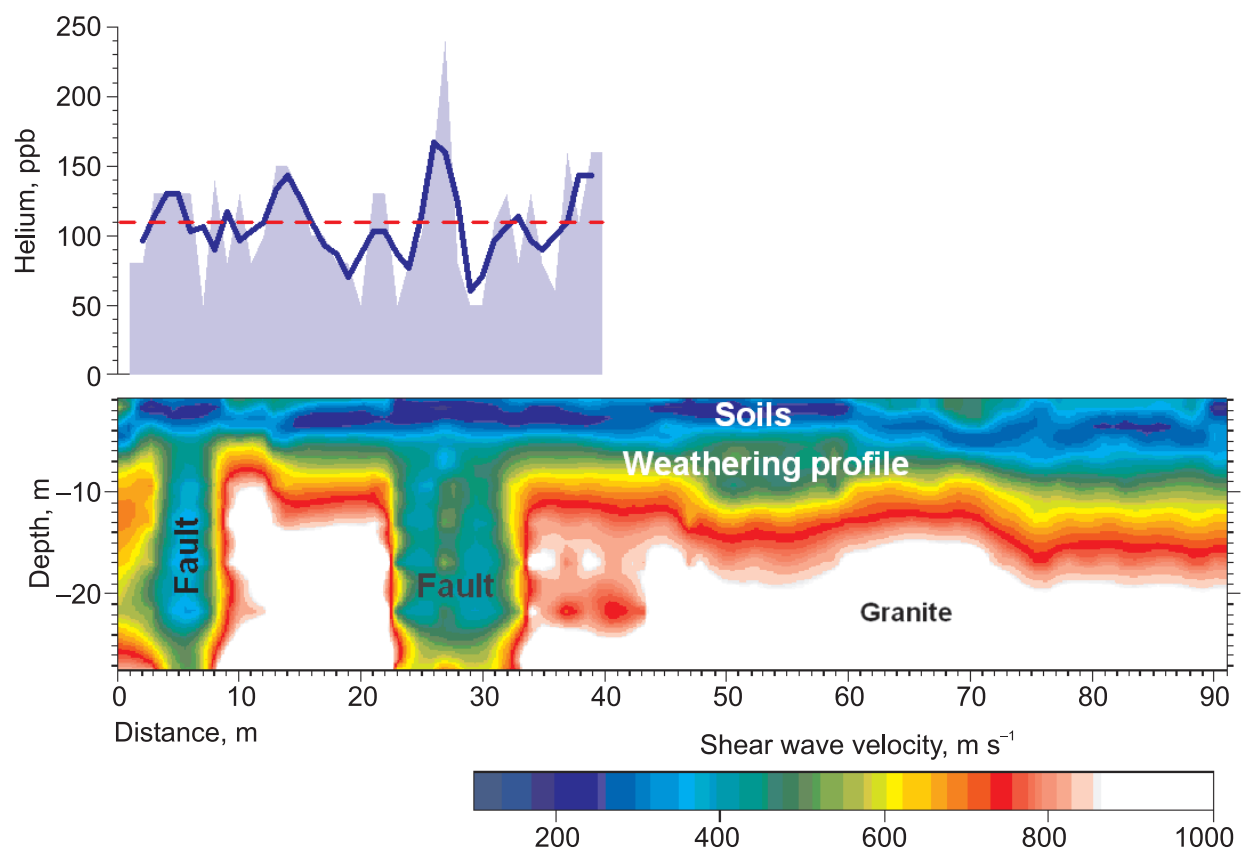

Figure 4. The shear wave velocity section and the soil-gas helium abundance along the profile 2. The original helium profile is superimposed by a three-point moving average plot (a thick blue line). The background soil-gas helium abundance along the profile is $110 \mathrm{ppb}$ above the atmospheric abundance of $5240 \mathrm{ppb}$ (a dashed line).

shallow granite basement terrain near Hyderabad (figures 3, 4 and 5). Integration of the results obtained from the two methods shows that the location of the soil-gas helium anomalies in general coincide with the vertical low-velocity zones in the shear-wave velocity sections. However, a few helium anomalies emerge where the velocity sections do not show any faults or fractures convincingly. The probable reason could be that the basement fractures/faults may not have undergone adequate chemical weathering that could be detected from the velocity sections. Alternatively, the fracture density may be so low that it may not reflect in the velocity sections. At places, the seismic sections point to faults and fractures, where soil-gas helium anomalies are apparently absent. In such cases, the fault/fracture zones may have been chemically altered to such an extent resulting 

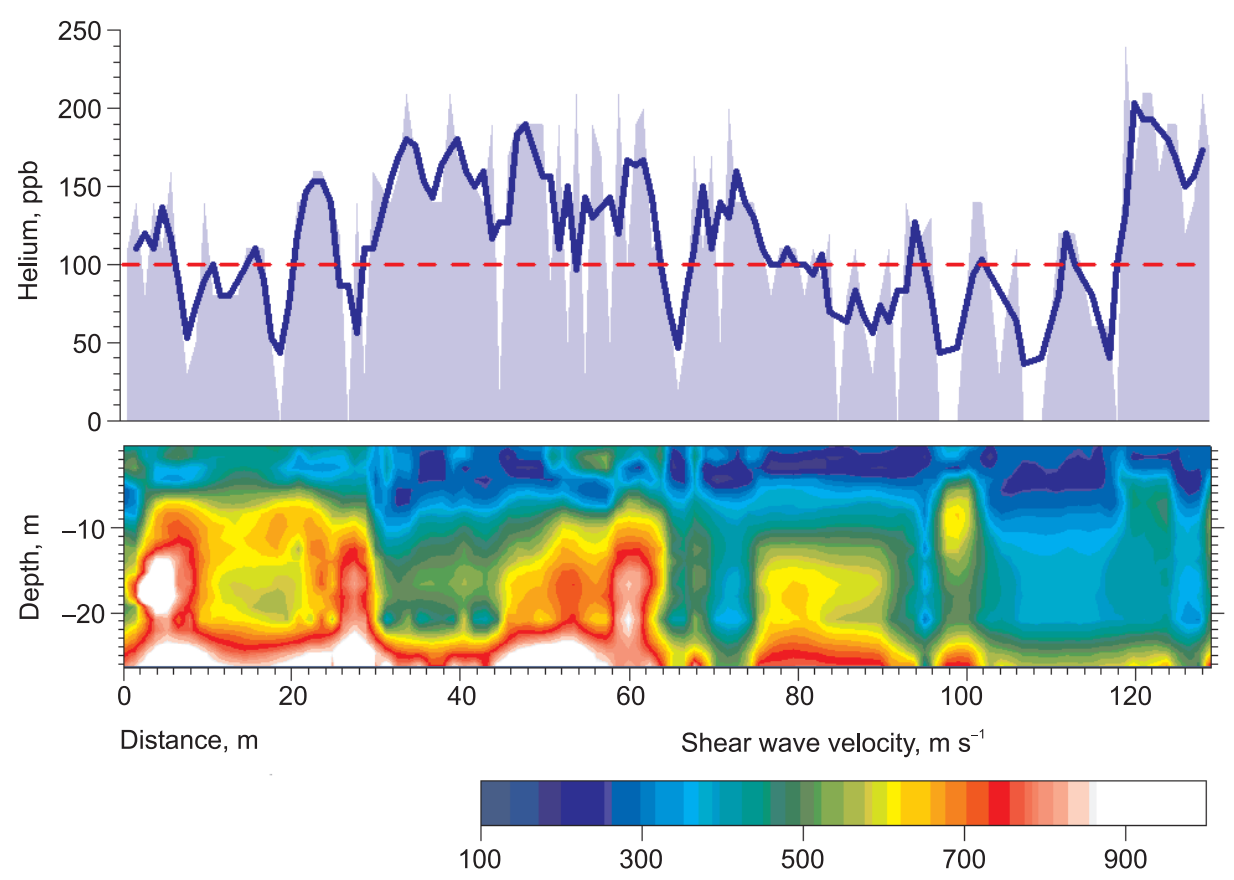

Figure 5. The shear wave velocity section and the soil-gas helium abundance along the profile 3 . The original helium profile is superimposed by a three-point moving average plot (a thick blue line). The background soil-gas helium abundance along the profile is $100 \mathrm{ppb}$ above the atmospheric abundance of $5240 \mathrm{ppb}$ (a dashed line).

in sealing of the apertures of these structures, thereby reducing the quantum of helium migration to the surface. For example, intense chemical weathering may produce abundant clays that may significantly hamper the migration of soil-gas helium upwards.

Studies by Gascoyne et al (1993) have shown that the soil-gas helium distribution might be indicative of groundwater mobility. The groundwater discharge zones are characterized by higher soil-gas helium content when compared to the recharge zones. By virtue of being easily dissolvable in groundwater and moving along with it, soil-gas helium can be considered as a useful indicator of groundwater flow direction. For example, in zones that contain stagnant groundwater, the dissolved helium can diffuse from the groundwater to the overlying rock and soil-cover. If the overlying rocks/soils are adequately permeable (owing to faults and fractures), the soil-gas helium can easily migrate to the surface and express itself as a soilgas helium anomaly (see the review by Toutain and Baubron 1999). Hence helium anomalies may be indicative of groundwater resource zones that are confined to fracture and fault zones.

The shear-wave velocity sections confirm the faults/fractures shown by the helium anomalies. The strength of the MASW survey is that it not only shows the fractures and faults, but also defines the bedrock configuration, weathering profiles and the soil cover. The velocity sections can help in selecting suitable sites for artificial recharge studies. For example, the fault zones characterized by lower velocity would have a higher recharge rate when compared to the adjoining fracture-free basement areas. Additionally, if the seismic low velocity zones (fault zones) show soil-gas helium anomalies, it is possible that the permeability of the fault zones may be higher than the fault zones without a helium anomaly. Therefore, an integration of these two tools would facilitate efficient mapping of the permeable fault zones.

\section{Conclusion}

The present study demonstrates that:

- the soil-gas helium emanometry and multichannel analysis of surface waves efficiently detect fractures and faults in a granite-gneiss province,

- the methods can be routinely used in imaging the groundwater resource zones in hard rock areas,

- the soil-gas helium anomalies may provide information of porosity and permeability of fault/fracture zones, and

- the shear wave velocity images show the natural recharge paths that may be connected to the deeper groundwater reservoir.

\section{Acknowledgements}

This work was undertaken under the CSIR Network Project, COR-0005. The authors thank the 
Director, NGRI for granting permission to publish this paper. We extend our thanks to all Engineering Geophysics Department members for the assistance in fieldwork. We are grateful to C Shankar, G Ramacharyulu and G Ramulu of the helium group for their co-operation. We specially thank Dave Hart for his helpful comments on an earlier version. The anonymous reviewers are thanked for their useful comments.

\section{References}

Chadwick B, Vasudev V N and Hegde G V 2000 The Dharwar craton, southern India, interpreted as the result of late Archaean oblique convergence; Precamb. Res. 99 91-111.

Condie K C 1993 Chemical composition and evolution of the upper continental crust: Contrasting results from surface samples and shales; Chem. Geol. 104 $1-37$.

Gascoyne M, Wuschke D M and Durrance E M 1993 Fracture detection and ground water flow characterization using He and Rn in soil gases, Manitoba, Canada; Appl. Geochem. 8 223-233.

Gupta H K, Rao R U M, Srinivasan R, Rao G V, Reddy G K, Dwivedy K, Banerjee D, Mohanty R and Satyasaradhi Y 1999 Anatomy of surface rupture zones of two stable continental region earthquakes, 1967 Koyna and 1993 Latur, India; Geophys. Res. Lett. 26 1985-1988.

Kumar P S and Reddy G K 2004 Radioelements and heat production of an exposed Archaean crustal cross-section, Dharwar Craton, south India; Earth Planet. Sci. Lett. 224 309-324.

Miller R D, Xia J, Park C B and Ivanov J 1999 Multichannel analysis of surface waves to map bedrock; The Leading Edge 18 1392-1396.
Park C B, Miller R D and Xia J 1999 Multi-channel analysis of surface waves; Geophysics 64 800-808.

Rao G V, Reddy G K, Rao R U M and Gopalan K 1994 Extraordinary helium anomaly over surface rupture of September 1993 Killari earthquake; Curr. Sci. 66 933-935.

Reimer G M 1985 Prediction of central California earthquakes from soil-gas fluctuations; Pure Appl. Geophys. $122369-375$.

Seshunarayana T, Prasad P P, Rao S V P P and Kousalya M 2006 Seismic surveys for earthquake microzonation of Jabalpur - A case study; In: Earthquake Mitigation, Preparedness, Seismic Vulnerability Assessment, National workshop on earthquake resistant design for the built environment (eds) Chapter T S et al 4.3.1.

Seshunarayana T, Senthil Kumar P, Sampath Rao V, Mysaiah D, Satish Kumar K and Pavan Kishore P 2008a Multichannel analysis of surface waves reveals shear zones and fractures in a shallow granite basement: Wailapally watershed near Hyderabad; J. Geol. Soc. India $\mathbf{7 1}$ 261-265.

Seshunarayana T, Satish Kumar K, Deenanadh S, Rama Mohan Rao Y and Senthil Kumar P 2008b Subsurface imaging of dolerite dykes in Hyderabad granite terrain using multichannel analysis of surface waves, In: Indian Dykes (eds) R K Srivastava, Ch Sivaji and N V Chalapathi Rao (New Delhi: Narosa Publishing House) pp. 331-338.

Toutain J-P and Baubron J-C 1999 Gas geochemistry and seismotectonics: A review; Tectonophys. 304 1-27.

Xia J, Miller R D, Park C B and Tian G 2002 Determining $Q$ of near-surface materials from Rayleigh waves; J. Appl. Geophys. 51 121-129.

$\mathrm{Xu}$ C and Butt S D 2006 Evaluation of MASW techniques to image steeply dipping cavities in laterally inhomogeneous terrain; J. Appl. Geophys. 59 106-116.

Xu Y, Xia J and Miller R D 2006 Quantitative estimation of minimum offset for multichannel surface-wave survey with actively exciting source; J. Appl. Geophys. 59 $117-125$. 